\title{
ALGUNAS REFLEXIONES EN TORNO AL PATRIMONIO CULTURAL INMATERIAL BOLIVIANO: UNA HISTORIA DE PROTECCIONISMO Y DE ESTATIZACIÓN
}

SOME REFLECTIONS ON THE BOLIVIAN INTANGIBLE CULTURAL HERITAGE: A HISTORY OF PROTECTIONISM AND NATIONALIZATION

Enviado em 04 de setembro de 2015 Aceito em 20 de novembro de 2015 Céline Geffroy ${ }^{1}$

Resumen: Bolivia es un país tan diverso que no se puede hablar de un solo patrimonio cultural inmaterial. Sin embargo, en vez de desvelar este patrimonio cultural tan rico, el Estado boliviano siempre buscó protegerlo mediante leyes punitivas que castigan el plagio y el "robo" de sus manifestaciones artísticas, impidiendo encontrar otros modos, más creativos, para favorecer la difusión de sus culturas. En este artículo, a partir del análisis de varias leyes patrimoniales departamentales y nacionales, analizo el discurso patrimonialista y proteccionista desde la Revolución nacionalista de 1952 hasta el Estado plurinacional actual.

Palabras-claves: Bolivia. Leyes de patrimonio cultural inmaterial. Proteccionismo.

Abstract: Bolivia is such a diverse country that it is not possible to speak about only one intangible cultural heritage. Nevertheless, instead of revealing this rich cultural heritage, the Bolivian state always sought to protect it through punitive laws against plagiarism and "theft" of its artistic manifestations, preventing from finding other more creative ways to incite the diffusion of its cultures. In this article, based on an analysis of various departmental and national heritage laws, I analyze the patrimonial and protectionist discourse from nationalist revolution of 1952 to the current multinational state.

Keywords: Bolivia. Intangible cultural heritage laws. Protectionism.

Bolivia es un país tan diverso que hablar de un solo patrimonio cultural inmaterial sería una aberración. La noción de "sociedad abigarrada", elaborada por el intelectual boliviano René Zavaleta (2008 [1986]), es probablemente la que mejor

1 Antropóloga, pesquisadora junto ao LAPCOS, Université de Nice, França. E-mail: celinageffroy@gmail.com 
interpreta esta diversidad cultural, social y geográfica, que abarca tanto a las "tierras altas" (andinas) como a las "tierras bajas" (Amazonía y el Chaco), pero también a las culturas "cholas" o mestizas, a los afrobolivianos y a las vigorosas culturas citadinas, vinculadas con el mercado, la globalización y los mass media.

En vez de desplegar ante el mundo un patrimonio cultural tan rico, el Estado boliviano siempre buscó proteger el acervo cultural mediante leyes punitivas que castigan el plagio y el "robo" de sus manifestaciones artísticas, impidiendo encontrar otros modos, más creativos, para favorecer la difusión de sus culturas. Más aún: la noción de patrimonio cultural inmaterial se convirtió en el dispositivo discursivo estratégico de la política cultural. Al respecto, es interesante subrayar el rol precursor del Estado boliviano para desarrollar el concepto de patrimonio cultural inmaterial, al enviar a la UNESCO, en 1973, una carta que proponía la "adjunción a la Convención de Ginebra de un nuevo protocolo que declarará propiedad de los Estados miembros las expresiones culturales de origen colectivo o anónimas que habían sido elaboradas o habían adquirido un carácter tradicional en su territorio. La firma de un acuerdo que apuntase a reglamentar la conservación, la promoción y la difusión del folklore, y la creación de un "Registro internacional de bienes culturales folklóricos", sobre la base de la Recomendación de 1964. La extensión de la competencia del Comité intergubernamental previsto por el artículo 10 de la Convención de Ginebra al estudio de los problemas que podría conllevar el protocolo propuesto, por ejemplo en caso de atribución a varios Estados, sobre la base de criterios científicos, de la 'paternidad' de expresiones comunes" (GUEVARA, 2011, 159).

La noción de patrimonio difiere según quien y como se la utiliza, puede transformarse en un arma de doble filo. Así, bajo el amparo de leyes patrimoniales proteccionistas, el Estado boliviano ha logrado modelar las percepciones de la población alrededor de la idea patrimonial de una manera que le permita controlar y apropiarse de sabidurías, de producciones folclóricas, artísticas et rituales indígenas o mestizas. El discurso patrimonialista ha inspirado y legitimado la aprobación de numerosas leyes destinadas a preservar y defender la autenticidad de la riqueza cultural boliviana. Es decir que en términos patrimoniales, el Estado boliviano es extremadamente conservador y punitivo. Esta es la hipótesis principal de este trabajo.

Con el fin de entender estos procesos proteccionistas, en primer lugar, propondré un análisis diacrónico del concepto de patrimonio desde 1952 hasta el Estado plurinacional actual. Mostraré que la intervención del Estado fue y sigue siendo muy significativa a lo largo de los diferentes ciclos históricos que vivió el país desde la Revolución de 1952, y que asistimos a una fuerte estatización del patrimonio acompañado de importantes leyes proteccionistas. $Y$ en un segundo momento, 
examinaré algunas leyes tanto a nivel departamental como nacionales para poner en evidencia su carácter proteccionista y punitivo.

\section{EL CICLO ESTATAL NACIONALISTA (1952-1985)}

La revolución nacionalista de 1952 inauguró un largo y conflictivo ciclo estatal que se desplegó, con diversos matices, hasta fines de la década de los 70s. Su modelo económico fue el capitalismo de Estado, organizado alrededor de grandes empresas mineras y petroleras. El Estado tuvo a su cargo la inversión en infraestructura, el monopolio del transporte ferroviario y aéreo y la asignación de tierras. Hasta fines de la década de los setenta, el Estado no era solamente el principal empleador e inversionista del país, sino también el principal comprador y exportador.

El Estado no fue solamente el principal actor político y económico, sino también el principal artífice del imaginario nacional. La idea de la cultura nacional adquirió una importancia estratégica: el patrimonio histórico-cultural fue presentado como un conjunto de bienes y prácticas tradicionales, heredadas del pasado, que constituyen a la nación y crean un sentimiento de pertenencia colectiva entre la población, situado por encima de los fuertes clivajes étnicos, regionales o socioeconómicos. Las políticas culturales, en consecuencia, estuvieron orientadas hacia la preservación, la restauración y la difusión de ese patrimonio.

El nacionalismo revolucionario fue pues un proyecto destinado a instituir una comunidad cultural -la nación boliviana- a través de un proceso de homogeneización cultural que fue imaginado como una feliz síntesis de un doble patrimonio, precolombino y español. La red donde circuló esta narrativa fue el sistema educativo, la política cultural y el servicio militar obligatorio, donde los campesinos debían hacer un aprendizaje de ciudadanía. El mestizaje se convirtió, de esta manera, en el contenido cultural y en la imagen recurrente de la identidad nacional. La implantación de una "lengua general" fue esencial; de ahí que la eliminación de la diversidad lingüística fuera asumida como un reto central de la construcción del Estado-nación.

El proteccionismo cultural implicó la creación de un sinfín de entidades patrimoniales, entre ellas el Instituto Boliviano de Cine, el Ministerio de Cultura Instituto Nacional de Arqueología, el Instituto Nacional de Antropología, el Instituto Nacional de Artes Plásticas, el Instituto Nacional de Historia y Literatura, el Instituto Nacional de Música y Arte Escénico, entre otros. Desde estas instituciones se generó un conjunto planificado de acciones e iniciativas destinadas a fortalecer la identidad nacional, y que fueron legitimadas por frondosa legislación patrimonialista. 


\section{EL CICLO ESTATAL NEOLIBERAL (1985-2000)}

La crisis del Estado del 52 dio paso a un nueva forma estatal, el Estado neoliberal, cuya emergencia coincide, por una parte, con la implementación del Programa de Ajuste Estructural (PAE) en 1985, que condujo a la liberalización de la economía y, por otra parte, con la consolidación de un régimen político basado en la democracia representativa y en la competencia electoral entre partidos políticos.

En el ámbito cultural, la era neoliberal estuvo caracterizada por dos tendencias centrales. Primero, se expresó en la apertura del mercado simbólico, la proliferación de empresas de comunicación (canales privados de Televisión, radios, empresas fonográficas, etc.) y el consiguiente rompimiento del monopolio del Estado en las telecomunicaciones, la aparición de universidades privadas, etc. Segundo, las reformas constitucionales de 1996 reconocieron a Bolivia como una nación multicultural y plurilingüe (Art. 1 de la Constitución), principio que se tradujo en políticas culturales multiculturales de cuño liberal. Sin embargo, esta política tuvo un alcance relativo sobre todo porque no implicó el empoderamiento de los pueblos indígenas.

De hecho, importa señalar que las políticas culturales públicas, hasta la década de los 90s, sufren pocas modificaciones. Las visiones que las orientan siguen determinadas por el paradigma nacionalista surgido en 1952. Así, el documento Políticas, Programas, Legislaciones y Guía Cultural (1997), plantea además que "toda política cultural de un Estado se asienta sobre dos pilares fundamentales: la defensa y preservación de su patrimonio cultural, así como la promoción del mismo tanto a nivel nacional como internacional" (1997: 21). Es decir, mientras la economía y la política se volvían neoliberales, las políticas culturales públicas seguían (y siguen) orientadas en una visión y discursividad nacionalista y proteccionista.

Finalmente, a partir del 2003, la cultura pasa a ser reconocida no sólo en su dimensión artística o patrimonial, sino como una dimensión económica importante y elemento estratégico para la generación de bienestar y empleo. De ahí que las funciones del Viceministro de Cultura se hayan orientado a generar políticas vinculadas con la economía.

\section{EL ESTADO PLURINACIONAL (2006-2013)}

En enero de 2009, se aprobó la nueva Constitución Política del Estado que instituye el Estado Plurinacional de Bolivia. Este acontecimiento fue resultado de la emergencia de poderosos movimientos sociales, de base indígena y campesina, que ocuparon el Estado a través de su instrumento electoral, el Movimiento Al Socialismo 
(MAS). Las principales transformaciones en la estructura estatal fueron: a) un sistema de gobierno que combina formas de la democracia representativa, con mecanismos de la democracia participativa, directa y comunitaria; b) La plurinacionalidad, expresada en la presencia directa (aunque limitada) de los pueblos indígenas originarios en las instancias de representación (Asamblea Legislativa Plurinacional y Asambleas Departamentales y en otras entidades estatales (Tribunal Constitucional, Órgano Electoral, entre otras); c) Un régimen de autonomías departamentales, regionales, municipales e indígenas, estas últimas en territorios de mayoría indígena, tanto en las "tierras altas" (andinas) como en las tierras bajas (llanuras orientales, amazonia y el Chaco).

La nueva Constitución reconoce que "dada la existencia pre-colonial de las naciones y pueblos indígena originario campesinos y su dominio ancestral sobre sus territorios, se garantiza su libre determinación en el marco de la unidad del Estado, que consiste en su derecho a la autonomía, al autogobierno, a su cultura, al reconocimiento de sus instituciones (Art. 2). Asimismo, reconoce 34 idiomas oficiales y postula un proyecto cultural basado en la descolonización (entendida como la desconstrucción del Estado mono-cultural) y la interculturalidad.

Esta política se ha expresado en una amplia participación en el diseño de las políticas culturales. Se ha creado un Consejo Plurinacional de Cultura y 9 Consejos Departamentales de Cultura, con atribuciones para proponer y poner en prácticas políticas públicas de desarrollo de las culturas, incidiendo fuertemente en la descentralización y la territorialización de la gestión cultural. Paralelamente, se ha aprobado una nueva ley educativa cuyas bases son la intra (se refiere al fortalecimiento interno de una cultura, por ejemplo el resguardo de su lengua) e interculturalidad, la revalorización de los saberes indígenas y la articulación con los diversos sistemas productivos.

El nuevo Estado ha hecho suyos los emblemas, símbolos e iconos del mundo indígena, por ejemplo la wiphala ha sido reconocida como la bandera de Bolivia, junto a la bandera tricolor republicana. Asimismo, han surgido nuevas narrativas históricas centradas en la resistencia anticolonial de los pueblos indígenas, que son reconocidas como legitimas por el Estado. No obstante, los modos de vida de la mayoría de los bolivianos, sobre todo en las ciudades, sus imaginarios, valores y códigos estéticos, siguen fuertemente orientados por el consumo, la acumulación capitalista y las industrias culturales.

Antes de cerrar este acápite, vale destacar que la política de la identidad desplegada en Bolivia en los últimos años, puede ser considerada como una verdadera política cultural debido a los dispositivos simbólicos, históricos, sentimentales, sonoros, 
identitarios que ha venido movilizando. Sin embargo, estas transformaciones coexisten paradójicamente con una fuerte ideología nacionalista, alentada y promovida desde el gobierno, que ha reforzado el paradigma proteccionista y patrimonialista en las políticas culturales. Aún más, esta política no ha resuelto los fuertes clivajes étnicos, culturales y regionales que caracterizan el tejido social boliviana, y que se expresan en altos niveles de racismo, discriminación, xenofobia y en la consolidación de divisiones con fuertes matices pigmentocráticos.

\section{ANÁLISIS DE LA NORMATIVA SOBRE EL PATRIMONIO CULTURAL}

\section{INMATERIAL}

En este contexto, pensar el patrimonio desde una perspectiva boliviana, desde luego, supone hacerlo en relación al Estado-nación que produce un discurso antiindígena camuflado puesto que busca antes que todo "integrar" lo indígena, domesticarlo. Se puede leer entonces a la patrimonialización como una forma sutil de expoliar el patrimonio inmaterial de los pueblos indígenas y campesinos a favor del Estado. Es peligroso. Criticar ese paradigma nacionalista implica reconocer "patrimonios" culturales, no estatales, que se han preservado por la vía de la memoria, de los mitos y de los rituales, como creaciones colectivas, sin propietarios individuales. Ahora bien, estas manifestaciones no se han mantenido en forma pura, pues se han combinado con lo moderno, luego el patrimonio debe abandonar la idea folclórica de pureza e incontaminación.

Todas las leyes concernientes al patrimonio recalcan el mismo deseo de protección (particularmente, lo veremos luego, contra el plagio), de promoción y difusión de este último, conforme por cierto con lo recomendado en la Convención para salvaguardar el patrimonio cultural inmaterial de la Unesco de 2003. Sin embargo, en la Constitución Política del Estado también se encuentra algunos artículos que muestran un exceso de estatización del patrimonio. Así, en el artículo 100 de la Constitución, se menciona que:

Es patrimonio de las naciones y pueblos indígena originario campesinos las cosmovisiones, los mitos, la historia oral, las danzas, las prácticas culturales, los conocimientos y las tecnologías tradicionales. Este patrimonio forma parte de la expresión e identidad del Estado.

A mis ojos, se trata de un enunciado ambiguo y hasta contradictorio entre el derecho a la autodeterminación de los pueblos indígenas y el papel del Estado puesto que primero se anuncia que el patrimonio intangible pertenece a las naciones que lo 
producen pero luego se enfatiza que forma parte de la esencia del Estado. Además, se menciona que el Estado es el encargado de proteger "los saberes y los conocimientos mediante el registro de la propiedad intelectual que salvaguarde los derechos intangibles de las naciones y pueblos indígena originario campesinas y las comunidades interculturales y afrobolivianas", sin precisar que otras iniciativas pueden ser tomadas.

Siguiendo al antropólogo, arqueólogo y etnomusicólogo boliviano Walter Sánchez (2001), la legislación concerniente a los bienes inmateriales de los pueblos indígenas y campesinos, tal como las manifestaciones folclóricas, la música, las danzas, las comidas, puede ser pensada como una forma de expropiación en este sentido que el patrimonio cultural de los indígenas y campesinos se vuelve propiedad del Estado. Es una especie de confiscación de parte del Estado a nombre del patrimonio que está muy ligado a toda forma de nacionalismo: etnonacionalismo, al nacionalismo departamental o nacional. Según Sánchez, la legislación sobre el patrimonio cultural representa una doble trampa para los indígenas: a esta expropiación de sus saberes, se añade una expropiación de su patrimonio tangible, es decir que su pasado se convierte en parte del Estado. A manera de ejemplo, la última ley de patrimonio de la gobernación de Cochabamba, que analizaré luego, menciona que todos los bienes patrimoniales hechos antes de 1950 pasan a ser del Estado.

En efecto, gracias a su nuevo estatuto autonómico (en vigencia desde 2010), los gobiernos autónomos tienen la facultad de promulgar leyes con el fin de poner en valor al patrimonio departamental. Así, por ejemplo, encontramos catalogado como patrimonio por la Gobernación de La Paz, el año 2006, el pan "marraqueta" (consumido a diario por los Bolivianos). Y más recientemente, en febrero 2011, la Mohoseñada, una danza ritual aymara del departamento de La Paz ligada con la época de lluvias, ha sido registrada como Patrimonio Cultural Intangible de la Música y Danza. Asimismo, en el caso del departamento de Cochabamba, el gobernador promulgó la Ley de Protección de Patrimonio Cultural a principios de octubre, que analizaré luego.

Finalmente, encontramos numerosos ejemplos de promulgación de leyes sobre el Patrimonio Cultural Inmaterial a nivel municipal que se inscriben en la misma visión constitucional del artículo 302 de la Constitución, parágrafo I, numerales 16) y 31) que señala que entre las competencias exclusivas de los gobiernos municipales autónomos, se encuentra la "promoción y conservación de cultura, patrimonio cultural, histórico, artístico, monumental, arquitectónico, arqueológico, paleontológico, científico, tangible e intangible municipal" y la "promoción de la Cultura y actividades artísticas en el ámbito de su jurisdicción", respectivamente. A manera de ejemplo, se puede mencionar que el gobierno autónomo municipal de La Paz ha declarado Patrimonio Cultural Intangible del Municipio de La Paz a la "cueca paceña" (una danza que se baila 
con pañuelos muy popular en los matrimonios) así como a 22 platos y bebidas tradicionales de La Paz.

En suma, las diferentes normas legales alrededor del Patrimonio Cultural Inmaterial persiguen varias metas: promover, rescatar y revalorizar ciertos aspectos de un patrimonio nacional o local o luchar contra lo que los legisladores llaman plagio y hacer valer la bolivianidad de tal patrimonio en una suerte de euforia proteccionista, como lo voy a exponer a continuación.

\section{ANÁLISIS CONCEPTUAL Y NORMATIVO SOBRE EL “PLAGIO”.}

Al revisar las leyes ligadas al patrimonio se hace evidente un deseo proteccionista exacerbado, el miedo permanente a ser desprovisto deslealmente de lo que se considera como propio. Parecería que la legislación boliviana tiende a protegerse permanentemente contra potenciales agresiones exteriores. Por esto, más que promulgar leyes propositivas, más constructivas, a favor del patrimonio, generalmente se discuten y se votan leyes de carácter punitivo y más particularmente leyes que son como una cruzada contra el plagio de parte de regiones o países vecinos.

La idea de plagio que motiva una parte de la legislación va - en realidad - en contra del espíritu de la convención de la Unesco de 2003 sobre el patrimonio cultural, puesto que se busca retraerse sobre su propia cultura en vez de difundirla más ampliamente y compartirla, que representa, finalmente, la mejor manera de proteger un patrimonio. La lectura de la convención muestra que se pretende salvaguardar el patrimonio ante su potencial desaparición o alteración; sin embargo, no se habla de usurpación, justamente porque el patrimonio es universal. Más bien, la convención subraya que el patrimonio cultural es inclusivo, es decir que algunas expresiones de nuestro patrimonio cultural inmaterial pueden ser similares a aquellas practicadas por otros. Ya sea que provengan de un pueblo cercado, de una ciudad del otro lado del mundo o que hayan sido adaptadas por pueblos que emigraron y se instalaron en otra región, todas pertenecen al patrimonio cultural inmaterial puesto que fueron transmitidas de generación en generación, que evolucionaron en reacción a su entorno y que contribuyen a procurarnos un sentimiento de identidad y de continuidad al establecer una relación con nuestro pasado $y$, mediante el presente, con nuestro futuro.

Asimismo, la convención recalca el aspecto representativo del patrimonio inmaterial, es decir que éste se desarrolla a partir de su arraigo en las comunidades y depende de las tradiciones, del know-how y de las costumbres que se transmiten al resto de la comunidad, de generación en generación, o a otras comunidades. Desde 
luego, el espíritu de la convención es una puesta a disposición del patrimonio al resto del mundo y más bien busca evitar un excesivo proteccionismo.

En este contexto, es complejo abordar el tema de la propiedad intelectual. Pienso que hay que distinguir entre el derecho de propiedad individual, cuando se conoce al autor, del derecho colectivo sobre cualquier creación. Además, cabe recalcar que el panorama cambia literalmente en contexto urbano. A menudo, se sobreponen los derechos individuales sobre los derechos colectivos y sobre los derechos humanos y se vuelve complicado desentrañar los hilos. En el caso de los bailes folclóricos es generalmente complejo proteger derechos de autor, ya pasaron al dominio público. Esta visión no mercantil es parte indisoluble de la identidad de los pueblos.

En Bolivia, el tema de los ritmos musicales de algunas regiones representa otra situación singular. Al respecto, Walter Sánchez (2001) comenta un hecho muy interesante. En el Norte de Potosí, como en todos los Andes, la "música" y la "poesía cantada" no pertenecen a nuestro mundo, el de los hombres (Kay Pacha), sino al mundo del Manqha Pacha, aquel de la oscuridad donde habitan los diablos y el Sereno. Según cuenta el etnomusicólogo, es este último quien 'saca' la 'música' y la 'poesía' y la 'entrega' a los hombres para que puedan asistir a las fiestas con ellas. Un "maestro de música" es encargado de "escuchar" la música y de transmitirla a los otros músicos. El sonido de los instrumentos musicales también le pertenece al Sereno que, dicen, vive en la oscuridad del instrumento. Es la razón por la cual, los músicos nunca dejan sus instrumentos en el piso, aunque estén muertos de borrachos, porque el sereno los puede romper. Por lo tanto, los músicos deben "serenarse" y dejar que el instrumento "toque por su cuenta" (SÁNCHEZ, comunicación personal). Por esto, las bandas (como los famosos Cocanis) siempre realizan rituales en las p'aqchas, las cascadas, los manantiales, donde vive su sereno. Existe entonces una relación peligrosa y compleja con el sereno así como con todos los seres que pueblan la Pachamama, la Tierra Madre. Los mundos de lo humano y lo no humano están imbricados.

Por mi parte, durante trabajos de campo que realice en tierras altas de la región de Cochabamba (en la comunidad campesina quechua de Qhoari), también escuche historias de demonios que hacían tocar el charango a hombres que habían atrapados y que atraían hacia dentro de las lagunas consideradas como agresivas. Y para tranquilizar estas mismas lagunas ávidas, los que pasan cerca tienen que tocar ciertas melodías que son como una ofrenda para apaciguar a los demonios del lugar.

Desde luego, la música y la poesía cantada no son una experiencia sensorial racional como lo es la composición musical en países europeos por ejemplo. La capacidad interpretativa de los músicos no es una cualidad humana. Al contrario, Sánchez piensa que es a-racional, no irracional, solo a-racional, porque puede 
manifestarse, por ejemplo, a través de los sueños. En suma, la "creación" musical es un acto no humano y su fruto pertenece al Sereno y a los diablos. ¿Cómo establecer entonces cualquier forma de "propiedad intelectual" o de "autoría"? Lo que quiero sugerir aquí es que es complejo reconocer en estas condiciones a autores personales de una música o de un hecho cultural - en el campo -, no se registran este tipo de autorías y por lo tanto, es complicado acusar de plagio en ciertas situaciones.

\section{UNA LEGISLACIÓN CONTRA EL PLAGIO}

El espectro del plagio es omnipresente. Así, recientemente se declaró, mediante decreto ley, a la morenada, kullawada, llamerada, caporales y saya afroboliviana "Patrimonio Cultural e Inmaterial del Estado Plurinacional de Bolivia" con el objetivo de frenar la constante apropiación indebida de las danzas folklóricas por parte de países vecinos. De esta manera, se pretende que el país y el resto del mundo reconozcan a estas danzas como bolivianas, puesto que en países vecinos, en anteriores años, los presentaron como parte de su folklore nacional. Asimismo, la declaratoria busca proteger a las danzas contra cualquier intento futuro de plagio o asimilación sin el reconocimiento de crédito y origen boliviano. No obstante, la cruzada contra el plagio corre el riesgo de transformarse en una nueva forma de colonización, así, Fernando Cajías, historiador, aunque reconociendo que "nos alegra que otros países difundan nuestra cultura", subraya que: "luchemos para bolivianizar el mundo con nuestra cultura, evitando la apropiación indebida". Por su parte, la ministra de Culturas, Elizabeth Salguero, habla en términos bélicos y evoca una verdadera cruzada contra el plagio: "una lucha abierta contra el plagio de nuestras manifestaciones culturales".

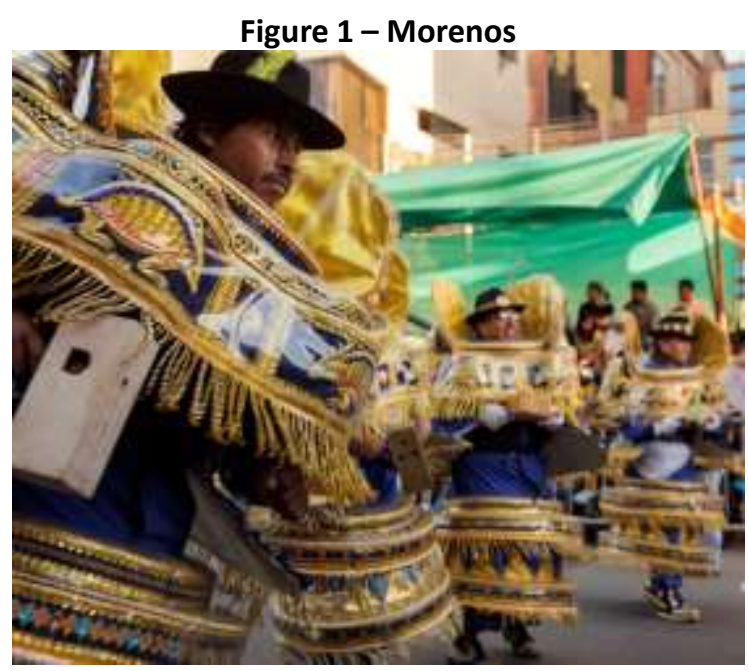

Fuente: Crédito fotográfico de Diego Julián González 
Qué pasa en los hechos? Todas las danzas presentes en el carnaval de Oruro, declarado obra maestra del Patrimonio oral e intangible de la Humanidad de la Unesco, son, desde sus inicios, encuentros entre por lo menos dos culturas. Por ejemplo, la diablada que representa la lucha entre el bien (San Miguel Arcángel) y el mal (los diablos) pone en escena a los siete pecados capitales, es una feliz mezcla de elementos de las religiosidades andina y cristiana. Pero va más allá. Después de ser consideradas danzas de la indiada, actualmente son las élites culturales y económicas que se apropian estas manifestaciones culturales. Ahora, no hay nada más prestigioso que bailar en una fraternidad de caporales para la elite paceña o cochabambina. $Y$ ello es un hecho que se repite. Las elites suelen apropiarse de elementos de las culturas indígenas o populares para producir legitimidad política, el gobierno nacionalista del MNR hizo esto con todos los símbolos indígenas en los años 50 y lo contrario es, a menudo, valido también. Lo que quiero sugerir es que no existe "pureza" antropológica en estos bailes folclóricos, se construyen, se recodifican paralelamente a los hechos históricos. El valor de las culturas y su sentido se desplazan y adquieren nuevas significaciones; sin embargo, los bienes culturales indígenas adquieren su real sentido al interior de su propia cultura. Es decir, sólo se puede comprender plenamente una cultura cuando estamos dentro de ella. Pero fragmentos de una cultura pueden ser recreados en otros contextos, países, etc. Significa que una cultura tiene también cierto valor universal.

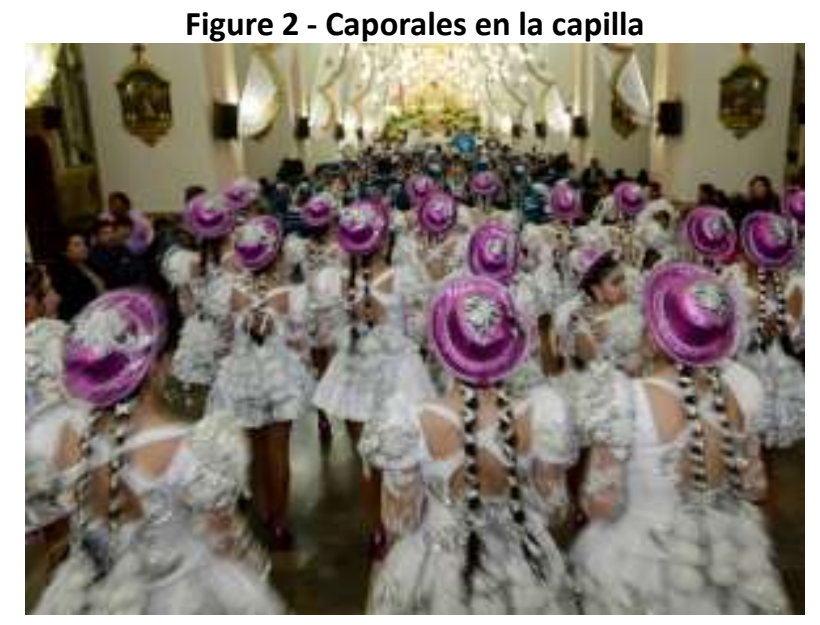

Fuente: Fotografía de Diego Julián González

Esta resignificación es particularmente visible en las fiestas que viajan en la maleta de los migrantes. Ellos añaden nuevos elementos fruto de la convivencia con su lugar de acojo. Así las fiestas en honor de la virgen de Urkhupiña en la Argentina (GIORGIS, 2000) o en Washington son distintas a la fiesta de "origen" de Quillacollo, sin que por ello sean menos interesantes y llenas de sentidos y portadoras de esperanza y de fe. Las fiestas y los bailes que las hacen no son monolíticos o estáticos. Viven y por 
esto no se pierden. Estoy convencida que es este mismo dinamismo la clave de su sobrevivencia, la garantía de su perpetuación. En vez de adoptar actitudes conservadoras y proteccionistas, pienso que hay que admitir el lado dinámico de la cultura y más bien incitar a su difusión puesto que las culturas ya no son comprensibles desde el ámbito meramente local o nacional, se han desterritorializado por obra de la globalización, las migraciones, y los mass media..

Retomando el ejemplo de la diablada, constatamos que Bolivia, Chile y Perú se disputan la paternidad de esta danza y que todos hacen sus propias investigaciones para asentar su legitimidad sobre la danza. Cada investigación pone en valor un dato distinto, los Peruanos sostienen que nace en el siglo XVI, en Chucuito, por obra de los Jesuitas y luego se expande a varias zonas del altiplano; los Chilenos piensan que pertenece a su propio folclore puesto que hace años (a finales de 1800 y principios de 1900) que se baila en la Tirana, cuando muchos mineros bolivianos que trabajaban en las salitreras trajeron sus danzas y músicas, y los Bolivianos pretenden que es meramente boliviana puesto que es el baile por excelencia en honor a la Virgen del Socavon de Oruro (DÍAZ ARAYA, 2011)... Seguramente, todos tienen algo de razón, porque en situación de frontera y en contexto migratorio, es normal que se vayan difundiendo manifestaciones culturales que los unos llevan y los otros se apropian. Ocurre lo mismo con la morenada y otras danzas altiplánicas.

Es que se trata de espacios geográficos con historia compartida, generalmente historias de migración, no solamente de gente sino de tradiciones, de costumbres y de fiestas, con símbolos en común. Entonces, en estas fiestas de ciudades fronterizas o próximas al territorio boliviano los sentidos van circulando. Yo creo que el destino de estos hechos folclóricos reside en su apropiación por los vecinos y es ciertamente esta importante difusión lo que consolida las danzas. Este dinamismo es el garante de la vigencia de este patrimonio inmaterial.

En suma, creo que evocar el concepto de plagio cuando se trata de manifestaciones culturales que ya pertenecen al dominio común es peligroso y hasta carece de sentidos, ya cobró vida propia, no obstante, en el caso que voy a presentar ahora, veremos que no es tan fácil determinar hasta donde un hecho cultural se puede apropiar y cuando empieza a ser un plagio. 


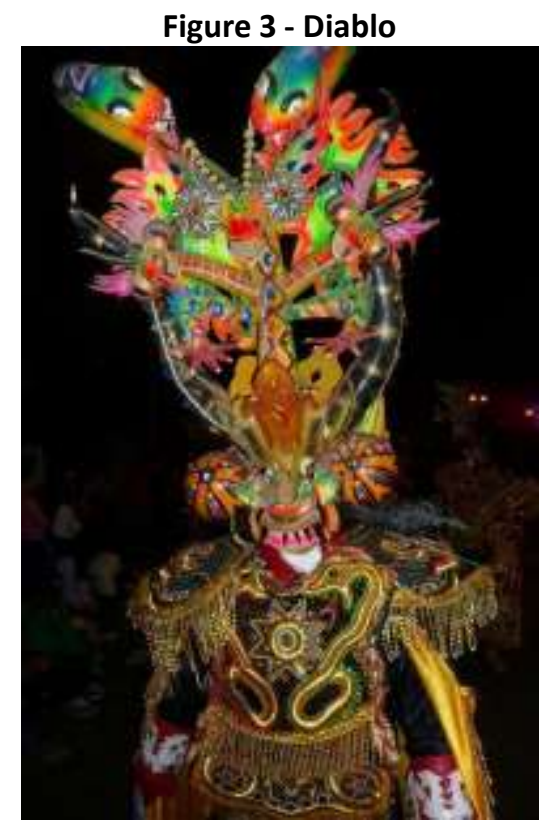

Fuente: Fotografía de Claire Billo

\section{PLAGIO Y PATRIMONIALIZACIÓN}

A principios de 2013, Do Re Mi, un grupo peruano de música folclórica, insertó en Youtube una canción titulada Oh Quillabamba Querida ${ }^{2}$. El hecho provocó un escándalo mediático y una ola de indignación en Bolivia, pues se trata de un indiscutible plagio de Oh Cochabamba Querida, una canción que está considerada como el "segundo himno" del departamento de Cochabamba ${ }^{3}$. Este incidente y su desenlace me permiten ilustrar mejor, a manera de ejemplo, mis argumentos en torno al plagio y a los problemas que suscita la política de la identidad en Bolivia. Veamos.

Consumado el plagio, la respuesta tanto del Gobierno Departamental como del Municipio de la ciudad capital de Cochabamba fue la aprobación de normas "duras" de resguardo patrimonial. Así, en junio de 2013, el Concejo Municipal de Cercado declaró mediante Ordenanza Municipal 4662/13 como Patrimonio Cultural Inmaterial e Intangible a la canción Oh Cochabamba Querida; la Asamblea Legislativa de Cochabamba promulgó luego una ley en los mismos términos puesto que se trata de "una manifestación y expresión popular de profunda identidad del pueblo cochabambino". También se determinó el traslado de los restos mortales del cantautor

\footnotetext{
2 Provincia de Cuzco, Perú.

3 La melodía y los versos de esta canción fueron originalmente publicadas en 1968 por el sello discográfico boliviano Lyra. Sus autores son Elías Blanco Mamani y Jaime del Río (seudónimo de Jaime del Río). Es interesante anotar que uno de los músicos peruanos, Edilberto Cuéllar, admitió que Do Re Mi tomó la canción del repertorio del ecuatoriano Jaime Ito, que la llevó a Perú y que, además, hay más versiones de otros grupos peruanos dedicadas a Quillabamba.
} 
Rubén Ramírez Santillán, de La Paz a Cochabamba, y el "homenaje y rendición de honores póstumos y su posterior traslado al lugar de los notables del Cementerio General de Cercado". Asimismo, se declaró el último lunes del mes de septiembre de cada año como día de la polémica, "encargando a todas las instituciones civiles y militares a preparar y desarrollar los actos protocolares correspondientes. Aún más, la brigada parlamentaria de Cochabamba presentó un proyecto de Ley ante la Asamblea Legislativa Plurinacional para declarar a esta obra como parte del patrimonio cultural boliviano.

Poco después, la Gobernación de Cochabamba promulgó la Ley de Patrimonio Cultural del Departamento, norma pionera en el país que tiene como objetivo la preservación de las diferentes manifestaciones culturales, identificar, catalogar, conservar y proteger la riqueza patrimonial del todo el departamento de Cochabamba, además de difundirla y ponerla en valor para el goce de las generaciones presentes y futuras.

En su Artículo 8, la Ley Departamental establece que el patrimonio cultural intangible abarca una constelación de manifestaciones culturales: concepciones, saberes, conocimientos y usos relacionados con la naturaleza y el universo; sistemas de organización económica, productiva, social, política territorial y cultural; idiomas, tradiciones, expresiones orales; juegos música, danza y cantos; rituales y actos festivos, medicina tradicional; técnicas artesanales. En mi opinión, esta disposición rebasa las definiciones tradicionales que se han elaborado en Bolivia sobre patrimonio intangible porque incluye expresiones culturales del mundo indígena y campesino, que no pueden ser comprendidas desde el código del folclore.

No obstante, el Artículo 9 determina que "El patrimonio cultural del Departamento pertenece a Cochabamba, esté o no, físicamente presente y/o registrado". Pienso que esta disposición es problemática porque integra y fusiona las manifestaciones culturales del mundo indígena en un pretendido patrimonio departamental, borrando de un plumazo su pertenencia legitima a los pueblos y naciones originarias. De hecho, al hablar de un acervo cultural "departamental" se integra las cosmovisiones originarias en una matriz cultural mestiza, encarnada en el Estado.

Más Aún: en el Artículo 30 de la mencionada ley, el Gobierno Autónomo Departamental se atribuye amplias facultades para proteger, conservar, declarar, registrar, inventariar, catalogar y promocionar el patrimonio departamental, municipal y comunitario. Estamos nuevamente frente a un modelo proteccionista que prescinde de las organizaciones indígenas, campesinas y, en general, de los actores e instituciones de la sociedad civil. Finalmente, el enfoque de la ley es punitivo, abunda en 
prohibiciones y responsabiliza penalmente a quienes atenten, comercialicen, destruyan o exporten bienes patrimoniales. Pienso que la gran paradoja de estas disposiciones radica en el hecho que las entidades estatales nacionales y/o departamentales no pueden garantizar el cumplimiento efectivo de estas normas. Pero además aquí surge el problema de determinar las ambiguas fronteras geográficas de la pretendida cultura cochabambina. De hecho, valga la anécdota, Oh Cochabamba Querida es un taquirari, un ritmo originario de los departamentos de Santa Cruz, Beni y Pando, cuyo autor es originario de la ciudad de La Paz.

\section{ALGUNAS REFLEXIONES FINALES...}

Desde la revolución nacionalista producida en la mitad del siglo pasado hasta el presente, los diferentes gobiernos que se sucedieron -dictatoriales o democráticosbuscaron todos fortalecer una identidad boliviana fundada sobre el discurso de la recuperación y difusión de su patrimonio cultural. No obstante, he intentado mostrar que una de las consecuencias de este proceso fue la apropiación por parte del Estado de las diversas expresiones culturales de los pueblos indígenas originarios, que se convirtieron en "propiedad" del Estado, bajo la justificación de ofrecer amparo y promoción ante amenazas externas. Dentro de este contexto, la noción de autoría se vuelve borrosa al volverse complejo desentrañar el origen de un autor particularmente cuando se trata de una creación colectiva, como en el caso de una comunidad indígena. Además, como lo vimos, las culturas indígenas perdieron sentido y significación al ser extraídas de sus contextos rituales y territoriales.

Asimismo, creo que actualmente estamos frente a un fuerte y complejo proceso de patrimonialización normativa que no sólo responde a la necesidad de defenderse frente al plagio y al saqueo cultural, sino también corresponde a una evidente demanda de identidad de las regiones, provincias y pueblos. Un dato relevante al respecto: desde el año 2010, cuando se instituye en Bolivia el régimen de autonomías y se crean las asambleas legislativas departamentales, solo en Cochabamba se han aprobado 23 leyes patrimoniales, entre ellas la declaratoria de "capital gastronómica de Bolivia", la declaratoria de Morochata como "capital de la producción de la papa", a Entre Ríos como la "capital hidrocarburífera", a Punata como "capital del rosquete" ${ }^{4}$. Con fines comparativos basta mencionar que sólo se aprobaron 4 leyes de seguridad ciudadana y ninguna relativa a investigación científica. Asimismo,

\footnotetext{
${ }^{4}$ Provincias de Cochabamba.
} 
desde el año 2006, inicio de la gestión del presidente Evo Morales, a la fecha la Asamblea Legislativa Plurinacional ha aprobado 134 leyes patrimoniales.

Me quedo con muchas dudas y preguntas: ¿Las leyes punitivas y las declaraciones simbólicas son instrumentos suficientes y efectivos para proteger el patrimonio tangible e intangible?, ¿Es posible encarar otra política cultural basada en la apertura de los patrimonios locales y nacionales al mundo? ¿Cómo des-estatizar la noción de patrimonio? Estas preguntas adquieren una mayor relevancia en el marco del nuevo ciclo estatal que enfatiza los principios de la plurinacionalidad y de la autodeterminación de los pueblos indígenas.

\section{REFERENCIAS}

BOLIVIA. Ministerio de Desarrollo Humano. Secretaría Nacional de Cultura. Políticas, programas, legislación y guía cultural. 1997.

DÍAZ Araya, Alberto. En la pampa los diablos andan sueltos: demonios danzantes de la fiesta del santuario de La Tirana. Rev. music. chil., vol. 65, n. 216, p. 58-97, 2011 . Disponible en: <http:// www.scielo.cl/scielo.php?script=sci_arttext\&pid=S0716-27902011000200004\&lng=es\&nrm=iso >. ISSN 0716-2790. <http://dx.doi.org/10.4067/S0716-27902011000200004>. Aceso en: 25 ago. 2014.

GIORGIS, Marta. Urkupiña, la virgen migrante fiesta, trabajo y reciprocidad en el boliviano gran córdoba. In: Cuad. Fac. Humanid. Cienc. Soc. Univ. Nac. Jujuy [online], n. 13, p. 233-250 , 2000. Disponible en: <http://www.scielo.org.ar/scielo.php?script=sci_arttext\&pid=S1668-810420000 00100014\&Ing=es\&nrm=iso>. ISSN 1668-8104. Aceso en: 22 ago. 2014.

GUEVARA, Manuel. Orígenes del patrimonio cultural inmaterial: la propuesta boliviana de 1973. Apuntes, v. 24, n. 2, p. 26-43, 2011.

SÁNCHEZ C., Wálter. Patrimonio, propiedad intelectual, autoría y "música indígena”. In: Memoria. CONGRESO INTERNACIONAL SOBRE PATRIMONIO HISTÓRICO E IDENTIDAD CULTURAL, 2., 2001, Cochabamba. Anales... Cochabamba: UMSS-Convenio Andrés BelloInstituto Internacional de Integración, 2001. p. 359-369.

ZAVALETA MERCADO, René (comp.). Lo nacional popular en Bolivia. México: Siglo XXI, 1986.

\section{CONVENCIÓN}

Convention pour la sauvegarde du patrimoine culturel immatériel de l'UNESCO. Disponible en: <http://www.unesco.org/culture/ich/fr/convention>. 2003. 


\section{LEYES CONSULTADAS}

Bolivia. Constitución Política del Estado. Disponible en: <http://www.gacetaoficialdebolivia .gob.bo/edicions/view/NCPE>. 2009.

Ley Número 134 de Patrimonio Histórico Cultural e Inmaterial del Estado Plurinacional de Bolivia relativa a la Danza "La Kullawada". Disponible en: <http://www.gacetaoficialdebolivia. gob.bo/normas/buscarg/kullawada>. 2011.

Ley Número 135 de Patrimonio Histórico Cultural e Inmaterial del Estado Plurinacional de Bolivia relativa a la Danza "La Morenada”. Disponible en: <http://www.gacetaoficialdebolivia. gob.bo/normas/buscarg/morenada>. 2011.

Ley Número 136 de Patrimonio Histórico Cultural e Inmaterial del Estado Plurinacional de Bolivia relativa a a la Danza "La Llamerada". Disponible en: <http://www.gacetaoficialdebolivia. gob.bo/normas/buscarg/llamerada>. 2011.

Ley Número 137 de Patrimonio Histórico Cultural e Inmaterial del Estado Plurinacional de Bolivia relativa a la Danza “Los Caporales”. Disponible en: <http://www.gacetaoficialdebolivia. gob.bo/normas/buscarg/caporales>. 2011.

Ley Número 138 de Patrimonio Histórico Cultural e Inmaterial del Estado Plurinacional de Bolivia relativa a la expresión artística cultural viva "Saya Afroboliviana”, perteneciente al Pueblo Afroboliviano. Disponible en: <http://www.gacetaoficialdebolivia.gob.bo/normas /buscarg/saya>. 2011.

Ley de Patrimonio Cultural del Departamento de Cochabamba. Disponible en: <http://lallajta.net/asambleafinal/index.php/es/legislacion/buscador-de-legislacion/item/406ley-del-patrimonio-cultural-del-departamento-de-cochabamba>. 2013.

Ley Número 363 de Patrimonio Cultural Intangible del Departamento de Cochabamba relativa a la canción Oh Cochabamba Querida. Disponible en: http://lallajta.net/asambleafinal/index.php /es/legislacion/buscador-delegislacion/itemlist/filter?searchword4=Cochabamba $\&=\&=\&=$ $\&=\&=\&$ searchword3=2013-2014\&=\&=\&=\&moduleld=119\&ltemid=303>. 2013. 